\title{
Elevated (Pro)renin Receptor Expression by Anti-Cancer Drugs, Carboplatin and Paclitaxel, in Cultured Cancer Cells: Possible Involvement of Apoptosis and Autophagy
}

\author{
Yurina Kashio-Yokota, ${ }^{1}$ Shigemitsu Sato, ${ }^{1}$ Takuo Hirose, ${ }^{1,2,3}$ Tomoki Watanabe, ${ }^{1}$ \\ Akari Endo, ${ }^{1,2}$ Fumihiko Watanabe, ${ }^{1}$ Moe Endo, ${ }^{1}$ Koji Ohba, ${ }^{1}$ Takefumi Mori ${ }^{2,3}$ \\ and Kazuhiro Takahashi ${ }^{1}$ \\ ${ }^{1}$ Department of Endocrinology and Applied Medical Science, Tohoku University Graduate School of Medicine, \\ Sendai, Miyagi, Japan \\ ${ }^{2}$ Division of Nephrology and Endocrinology, Faculty of Medicine, Tohoku Medical and Pharmaceutical \\ University, Sendai, Miyagi, Japan \\ ${ }^{3}$ Division of Integrative Renal Replacement Therapy, Faculty of Medicine, Tohoku Medical and Pharmaceutical \\ University, Sendai, Miyagi, Japan
}

(Pro)renin receptor $[(P) R R]$ is a component of the renin-angiotensin system and plays an essential role in the activity of vacuolar $\mathrm{H}^{+}$-ATPase and autophagy. (P)RR is expressed in cancer cells. However, the relationship among $(P) R R$, apoptosis and autophagy in the treatment of anti-cancer drugs has not been clarified. The aim of this study was to clarify the effects of anti-cancer drugs with autophagy-promoting activity on (P)RR expression in cancer cells. MCF-7 breast cancer cells and A549 lung cancer cells were treated with carboplatin or paclitaxel, and the expression of $(P) R R$, apoptosis markers and autophagy markers were assessed by RT-qPCR, western blot analysis and immunocytochemistry. Expression levels of $(\mathrm{P}) \mathrm{RR}$ mRNA and soluble $(\mathrm{P}) \mathrm{RR}$ protein were increased by carboplatin or paclitaxel in a dose-dependent manner. Immunofluorescence staining of (P)RR was increased in both MCF-7 and A549 cells treated by carboplatin or paclitaxel. Apoptosis induction was shown by elevated BAX/BCL2 mRNA levels and increased active caspase3-positive cells. Moreover, autophagy induction was confirmed by increased levels of autophagy-associated mRNAs and LC3B-Il proteins. (P)RR knockdown by (P)RR-specific siRNA suppressed the cell viability in MCF-7 cells and A549 cells under the treatment of carboplatin or paclitaxel, suggesting that $(P) R R$ deficiency inhibits the proliferation of cancer cells in a pathway different from carboplatin or paclitaxel. The present study showed that the expression of (P)RR mRNA and soluble (P)RR was increased by anti-cancer drugs with autophagy-promoting activity. Upregulated (P)RR and autophagy may constitute a stress adaptation that protects cancer cells from apoptosis.

Keywords: apoptosis; autophagy; cancer; (pro)renin receptor; vacuolar $\mathrm{H}^{+}$-ATPase

Tohoku J. Exp. Med., 2021 October, 255 (2), 91-104.

\section{Introduction}

(Pro)renin receptor $[(\mathrm{P}) \mathrm{RR}]$ is identified as a single transmembrane receptor that binds specifically to renin and its precursor, prorenin (Nguyen et al. 2002; Nguyen and Muller 2010; Nguyen 2011). (P)RR has three molecular forms; a 35-kDa full-length (P)RR, a 28-kDa soluble
(P)RR, and a truncated (P)RR (M8-9 fragment). (P)RR has received much attention in recent years because it was shown to have functions that are both dependent on and independent of the renin angiotensin system. (P)RR, particularly a truncated (P)RR, is considered to form a functional complex with vacuolar $\mathrm{H}^{+}$-ATPase (V-ATPase) (Nguyen 2011). (P)RR has another name of ATP6AP2

Received June 1, 2021; revised and accepted July 21, 2021. Published online October 14, 2021; doi: 10.1620/tjem.255.91.

Correspondence: Takuo Hirose, Ph.D., Department of Endocrinology and Applied Medical Science, Tohoku University Graduate School of Medicine, 2-1 Seiryo-machi, Aoba-ku, Sendai, Miyagi 980-8575, Japan.

e-mail: hirose-t@med.tohoku.ac.jp

Kazuhiro Takahashi, M.D., Ph.D., Department of Endocrinology and Applied Medical Science, Tohoku University Graduate School of Medicine, 2-1 Seiryo-machi, Aoba-ku, Sendai, Miyagi 980-8575, Japan.

e-mail: ktaka-md@med.tohoku.ac.jp

(C)2021 Tohoku University Medical Press. This is an open-access article distributed under the terms of the Creative Commons Attribution-NonCommercial-NoDerivatives 4.0 International License (CC-BY-NC-ND 4.0). Anyone may download, reuse, copy, reprint, or distribute the article without modifications or adaptations for non-profit purposes if they cite the original authors and source properly.

https://creativecommons.org/licenses/by-nc-nd/4.0/ 
(ATPase, $\mathrm{H}^{+}$transporting, lysosomal accessory protein 2). $\mathrm{V}$-ATPase is responsible for the active transport of protons and maintains the acidity of intracellular compartments and the extracellular environment (Forgac 2007).

(P)RR is expressed in various types of normal and tumor cells. We have shown that $(\mathrm{P}) \mathrm{RR}$ is expressed in breast cancers (Ohba et al. 2014), lung cancers (Ohba et al. 2020) and adrenal tumors (Yamamoto et al. 2013). Suppression of (P)RR expression by $(\mathrm{P}) \mathrm{RR}$ siRNA reduced cell proliferation in cultured breast carcinoma cells (MCF-7 cells and SK-BR-3 cells) (Ohba et al. 2014) and lung carcinoma cells (A549 cells) (Ohba et al. 2020). V-ATPase is essential for lysosomal acidification and autophagy (Mauvezin et al. 2015). Cell-specific, conditional knockout mice of (P)RR gene (ATP6AP2) showed the suppression of the V-ATPase activity and autophagy, and cell death of cardiomyocytes (Kinouchi et al. 2010) or podocytes in the kidney (Oshima et al. 2011; Riediger et al. 2011). Suppression of (P)RR expression may inhibit lysosomal acidification and autophagy, and suppress proliferation of cancer cells.

In addition, (P)RR functions as an adaptor between Wnt receptors and the V-ATPase complex, and regulates the $\mathrm{Wnt} / \beta$-catenin pathway, which is essential in cell development and differentiation, and the pathophysiology of diseases, such as cancer (Cruciat et al. 2010; Bernhard et al. 2012). It has been suggested that (P)RR plays an important role in $\mathrm{Wnt} / \beta$-catenin signaling-dependent genesis of pancreatic ductal adenocarcinoma (Shibayama et al. 2015), glioma (Kouchi et al. 2017) and colorectal cancer (Wang et al. 2019).

We have shown that bafilomycin A1 or chloroquine inhibited autophagy and reduced the cell viability in MCF-7 breast cancer cells and A549 lung adenocarcinoma cells with increased intracellular accumulation of soluble (P)RR (Endo et al. 2020). In contrast, anti-cancer drugs, carboplatin and paclitaxel, are known to induce autophagy (Chi et al. 2013; Desai et al. 2013; Liu et al. 2013). However, effects of carboplatin and paclitaxel on (P)RR expression have not been studied. Carboplatin, a platinum-containing anti-cancer drug, reacts by cross-linking to double strands of DNA, inhibits replication and subsequently induces apoptosis in cancer cells. Carboplatin is widely used for the treatment of various cancers including breast cancer (von Minckwitz et al. 2014; Tutt et al. 2018) and non-small cell lung cancer (Rossi et al. 2012; Griesinger et al. 2019). Paclitaxel is a microtubule-stabilizing agent which interferes with spindle microtubule dynamics and causes cell cycle arrest and apoptosis (McGrogan et al. 2008). It is also widely used in chemotherapy for breast cancer (McGrogan et al. 2008) and non-small cell lung cancer (Murphy et al. 1993). The aim of the present study was to clarify effects of anti-cancer drugs with autophagy-inducing activity on the (P)RR expression in cultured human cancer cells.

\section{Materials and Methods}

\section{Cell cultures}

A human breast cancer cell line, MCF-7 (No. RCB1904) and a human lung cancer cell line, A549 (No. RCB3677) were obtained from RIKEN BRC Cell Bank (Tsukuba, Japan), as previously reported (Endo et al. 2020). MCF-7 cells were cultured in Roswell Park Memorial Institute (RPMI) 1640 medium (Thermo Fisher Scientific Inc., Waltham, MA, USA) containing 10\% fetal bovine serum (FBS; Thermo Fisher Scientific Inc.). A549 cells were cultured in Dulbecco's modified Eagle's medium (DMEM; Thermo Fisher Scientific Inc.) containing 10\% FBS. The cells were cultured at $37^{\circ} \mathrm{C}$ in a humidified atmosphere under $5 \% \mathrm{CO}_{2}$.

After 24 hours of seeding, the cells were treated with vehicle, carboplatin (final concentration: 10,50 or $100 \mu \mathrm{M}$; FUJIFILM Wako Pure Chemicals, Osaka, Japan) or paclitaxel (final concentration: 1, 5 or $10 \mathrm{nM}$; FUJIFILM Wako Pure Chemicals). After 5, 24, and 48 hours of incubation, the cells were harvested for mRNA expression analysis. After 72 hours of treatments, the cells were used for western blot analysis and immunofluorescence staining. The cell proliferation assay was performed 48 hours after administration of carboplatin or paclitaxel by WST-8 method as previously described (Endo et al. 2020).

In the experiments using siRNA, both cells were transfected after 24 hours of seeding with either of 4 sequences of siRNAs for (P)RR (ON-TARGETplus Human ATP6AP2 siRNA, LQ-013647-01-0020; Dharmacon, Lafayette, CO, USA) or scrambled RNA (scRNA; control) (ON-TARGETplus Non-targeting Pool, D-001810-10-20; Dharmacon) using Lipofectamine 2000 (Thermo Fisher Scientific Inc.) and Opti-MEM I reduced serum medium (Thermo Fisher Scientific Inc.), as previously described (Hirose et al. 2019).

\section{Real-time quantitative polymerase chain reaction (RT-qPCR) analysis}

Total RNA was extracted from cultured cells using FastGene RNA Basic Kit (Nippon Genetics, Tokyo, Japan). Complementary DNA (cDNA) was synthesized using oligonucleotides (dT), random primers and PrimeScript Reverse Transcriptase (TaKaRa Bio, Kusatsu, Japan). Five nanograms of cDNA were used as a template for qPCR. The target sequences were amplified in duplicate with genespecific primers (Table 1) using THUNDERBIRD SYBR qPCR Mix (TOYOBO, Osaka, Japan) and the CFX96 RealTime PCR Detection System (Bio-Rad Laboratories, Hercules, CA, USA). Relative mRNA expression levels were normalized to ribosomal protein lateral stalk subunit P2 (RPLP2) mRNA expression levels.

\section{Western blotting}

Western blot analysis was performed following our previous report with some modifications (Endo et al. 2020). 
Table 1. List of primers for reverse transcriptase-polymerase chain reaction (RT-PCR).

\begin{tabular}{lll}
\hline \multicolumn{1}{c}{ Gene } & \multicolumn{1}{c}{ Forward } & \multicolumn{1}{c}{ Reverse } \\
\hline (P)RR & CCTCCCTCATTAGGAAGACAAGGAC & TCGAATCTTCTGGTTTGTCATCCT \\
BAX & ATGTTTTCTGACGGCAACTTC & ATCAGTTCCGGCACCTTG \\
BCL2 & GATGTGATGCCTCTGCGAAG & CATGCTGATGTCTCTGGAATCT \\
VAMP8 & AAGCCACATCTGAGCACTTCAA & CCAGTGGCAAAGAGCACAATG \\
DRAM1 & GTCAACCCCTTCCTCCCGTA & TCGTGGCTGCACCAAGAAAT \\
RPLP2 $*$ & Catalog \#HA067804 & \\
\hline
\end{tabular}

*RPLP2 primer set was purchased from TaKaRa Bio (Kusatsu, Japan), and the reference number (primer set ID) was indicated.

(P)RR, (pro)renin receptor; BAX, Bcl-2-associated X protein; VAMP8, vesicle-associated membrane protein 8; DRAM1, DNA damage-regulated autophagy modulator 1; RPLP2, ribosomal protein lateral stalk subunit $\mathrm{P} 2$.

Table 2. List of antibodies used.

\begin{tabular}{llccccc}
\hline \multicolumn{1}{c}{ Antigen } & \multicolumn{1}{c}{ Company } & Catalog \# & Clone & Host & IF & WB \\
\hline (P)RR & In house* & & & Rabbit & $1: 1,000$ & $1: 10,000$ \\
LC3 & Cell Signaling Technology, Danvers, MA, USA & 12741 & D3U4C & Rabbit & $1: 5,000$ \\
Active CASP3 & BD Pharmingen Inc., San Diego, CA, USA & 559565 & C92-605 & Rabbit & $1: 500$ & $1: 1,000$ \\
ACTB & Sigma-Aldrich Japan, Tokyo, Japan & A2978 & AC-15 & Mouse & $1: 10,000$ \\
\hline
\end{tabular}

*Anti-(P)RR antibody was generated by immunizing rabbits with synthetic human (P)RR ${ }_{224-237}$ (Hirose et al. 2009).

(P)RR, (pro)renin receptor; LC3, microtubule-associated protein light chain 3; CASP3, caspase-3; ACTB, $\beta$-actin; IF, immuno-

fluorescence; WB, western blotting.

Briefly, harvested cells were washed once with ice-cold phosphate-buffered saline (PBS), and were lysed with M-PER Mammalian Protein Extraction Reagent (Thermo Fisher Scientific Inc.) containing Halt protease and phosphatase Inhibitor Cocktail (Thermo Fisher Scientific Inc.). The mixture was robustly vortexed for $10 \mathrm{~min}$ and centrifuged at $19,000 \times \mathrm{g}$ for $15 \mathrm{~min}$ at $4^{\circ} \mathrm{C}$. The supernatant was stored at $-80^{\circ} \mathrm{C}$ until sodium dodecyl sulfate-polyacrylamide gel electrophoresis (SDS-PAGE). The protein concentration of the supernatant was quantified by the Bradford method. The cell lysates (15 $\mu \mathrm{g}$ protein/lane) were subjected to SDS-PAGE (15\% SDS polyacrylamide gel, $200 \mathrm{~V}$ ) and transferred to polyvinylidene difluoride membranes by using the Trans-Blot Turbo system (Bio-Rad Laboratories). The membranes were blocked in Blocking Reagent (FUJIFILM Wako Pure Chemical) for 60 min with shaking at room temperature, and then incubated with the primary antibodies (Table 2) overnight at $4^{\circ} \mathrm{C}$. All primary antibodies were diluted in Can Get Signal Immunoreaction Enhancer Solution (TOYOBO). The membrane was reacted with secondary antibodies, horseradish peroxidase (HRP)-conjugated anti-rabbit IgG or HRP-conjugated antimouse IgG (both 1:10,000; Santa Cruz Biotechnology, Dallas, TX, USA), diluted in Can Get Signal Immunoreaction Enhancer Solution at $4^{\circ} \mathrm{C}$ for 60 minutes. The signals were visualized using Immobilon Western (Merck Millipore, Billerica, MA, USA) and photographed using the ChemiDoc ${ }^{\mathrm{TM}}$ Touch Imaging System (BioRad Laboratories). The intensity of the detected bands was quantified by Image $\mathrm{J}$ software.

\section{Immunofluorescence staining}

MCF-7 and A549 cells cultured on glass slides (12 $\mathrm{mm}$; Matsunami Glass, Osaka, Japan) were fixed with $4 \%$ paraformaldehyde (FUJIFILM Wako Pure Chemical) for 20 min and permeated with $0.1 \%$ Triton-X 100 (Merck KGaA, Darmstadt, Germany) in PBS for $10 \mathrm{~min}$. After blocking with $5 \%$ bovine serum albumin/PBS, the cells were incubated with primary antibody (Table 2) overnight at $4^{\circ} \mathrm{C}$. After washing 3 times with PBS, the cells were reacted with anti-rabbit IgG-Alexa 555 (1:1,000; Thermo Fisher Scientific Inc.) for 30 minutes at room temperature, and then mounted with DAPI Fluoromount-G (SouthernBiotech, Birmingham, AL, USA). The images were acquired using a fluorescence microscope (BZ-X710; KEYENCE, Tokyo, Japan) or a confocal laser scanning microscope (Leica TCS SP8; Leica Microsystems, Wetzlar, Germany).

\section{Statistical analyses}

All data were given as mean \pm standard error of the mean (SEM). JMP pro (ver. 15.1; SAS Institute Inc., Cary, NC, USA) was used for statistical analysis. Comparisons were made using one-way analysis of variance (ANOVA), followed by Tukey-Kramer method for multiple comparisons. A $p$-value of less than 0.05 was considered statistically significant. 


\section{Results}

Effects of anti-cancer drugs on $(P) R R$ expression

The time course study of carboplatin showed that expression levels of (P)RR mRNA were increased 1.4-fold $(p<0.0001)$ at 48 hours in MCF-7 cells (Fig. 1a, upper panel), and 1.3-fold $(p<0.01)$ at 24 hours and 1.8-fold ( $p<$ 0.0001 ) at 48 hours in A549 cells (Fig. 1b, upper panel) after the addition of carboplatin $(100 \mu \mathrm{M})$. Expression levels of (P)RR mRNA were also increased 1.3-fold $(p<0.01)$ at 48 hours in MCF-7 cells (Fig. 1a, lower panel), and 1.4fold $(p<0.01)$ at 48 hours in A549 cells (Fig. 1b, lower panel) after the addition of paclitaxel $(10 \mathrm{nM})$, respectively.

Changes in $(\mathrm{P}) \mathrm{RR}$ protein expression levels by carboplatin (Fig. 2) or paclitaxel (Fig. 3) were then studied by western blot analysis in MCF-7 and A549 cells. The (P)RR antibody raised against the extracellular domain of (P)RR was used in western blot analysis, and therefore, recognizes both full-length (P)RR and soluble (P)RR (Hirose et al. 2009). The cells were cultured for 72 hours in the culture medium containing carboplatin $(10,50$ and $100 \mu \mathrm{M})$ or paclitaxel $(1,5$ and $10 \mathrm{nM})$. Treatment with carboplatin increased expression levels of full-length (P)RR at $100 \mu \mathrm{M}$ (1.2-fold, $p<0.05$ compared to control) and soluble (P)RR at 50 and $100 \mu \mathrm{M}$ (2.2-fold, $p<0.05$ and 3.0-fold, $p<0.01$ compared to control, respectively) in MCF-7 cells (Fig. 2a). Treatment with carboplatin increased expression levels of soluble (P)RR at $100 \mu \mathrm{M}$ (3.8-fold, $p<0.05$, compared to control) in A549 cells, whereas no significant increase was observed in expression levels of full-length (P)RR protein (Fig. 2b). Treatment with paclitaxel increased expression levels of soluble (P)RR at $10 \mathrm{nM}$ in both MCF-7 (Fig. 3a) and A549 cells (Fig. 3b) (4.5-fold, $p<0.05$, and 2.4-fold, $p$ $<0.05$, compared to control, respectively), whereas no significant increase was observed in expression levels of fulllength $(\mathrm{P}) \mathrm{RR}$ protein in both the cells.

Immunofluorescence staining showed enhanced (P)RR immunoreactivity in the cytoplasm of MCF-7 and A549 cells treated with carboplatin $(100 \mu \mathrm{M})$ (Fig. 4, middle column) or paclitaxel (10 $\mathrm{nM}$ ) (right column), compared with (a) MCF-7
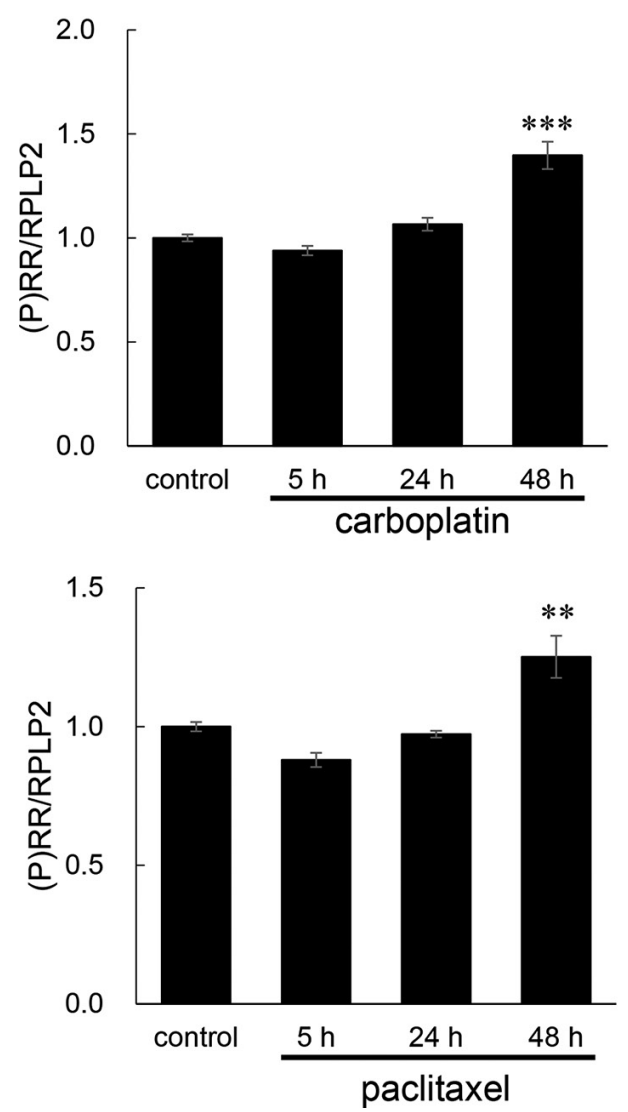

(b) A549
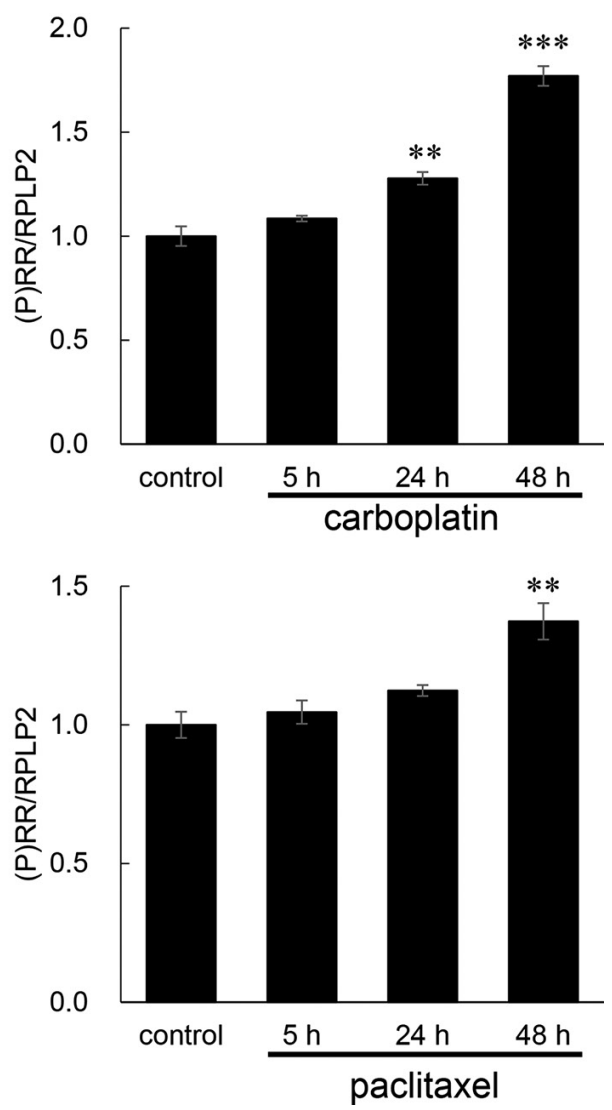

Fig. 1. The time course study of (pro)renin receptor [(P)RR] mRNA expression by carboplatin or paclitaxel in MCF-7 and A549 cells.

(a, b) Relative expression levels of (P)RR mRNA levels in MCF-7 cells (a) and A549 cells (b) treated with carboplatin $(100 \mu \mathrm{M})$ (upper panel) or paclitaxel $(10 \mathrm{nM})$ (lower panel) for 5, 24 and $48 \mathrm{~h}$. (P)RR mRNA levels were analyzed by RT-qPCR. The (P)RR mRNA levels are normalized to ribosomal protein lateral stalk subunit P2 (RPLP2) mRNA levels and shown as the relative mRNA levels to the control (the mean of control $=1$, mean $\pm \mathrm{SEM}, n=4$ ). ${ }^{* *} p<0.01, * * * p$ $<0.0001$ compared with control. 
(a) MCF-7
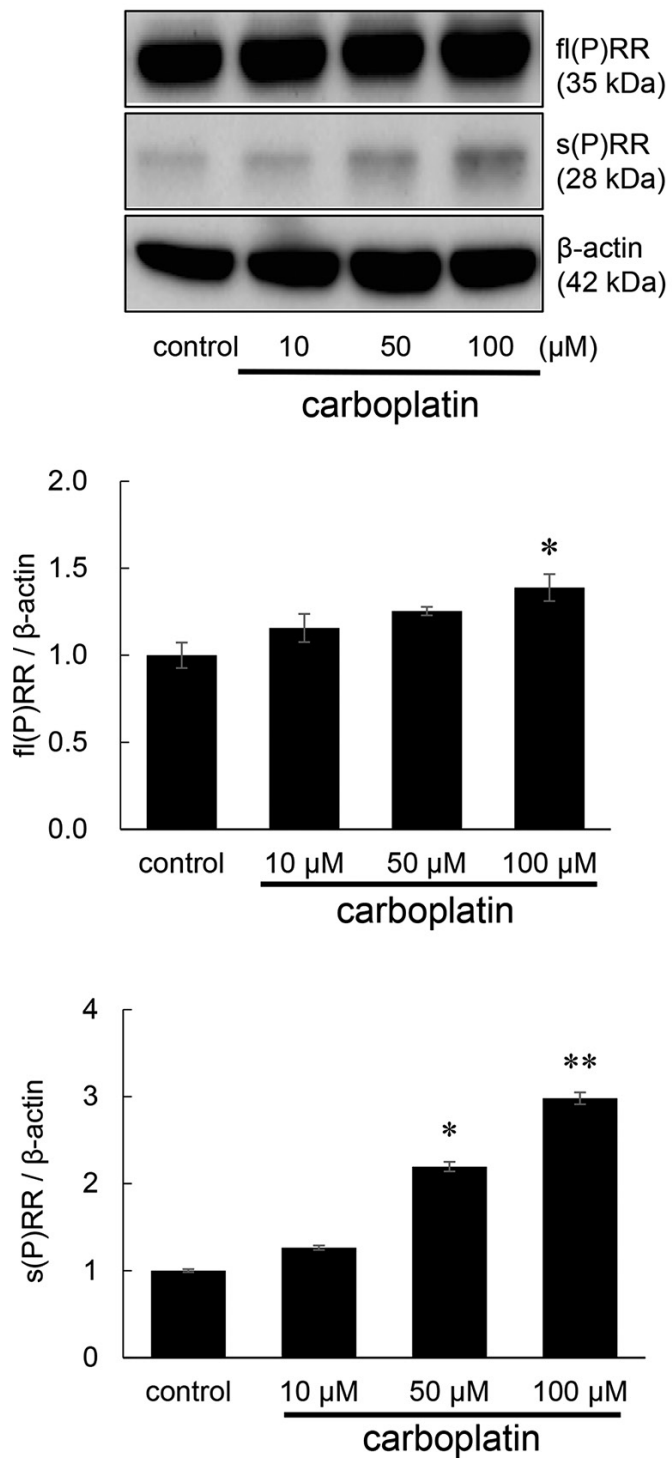

(b) A549
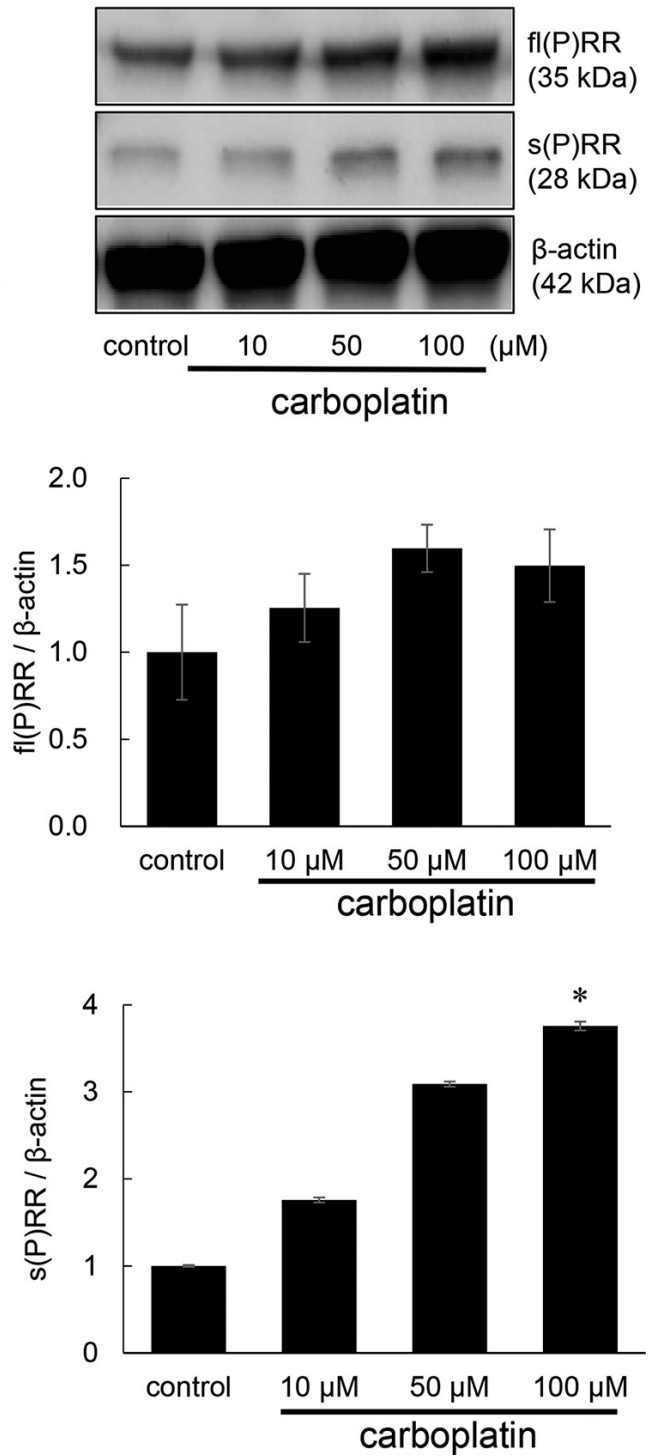

Fig. 2. Increased soluble (pro)renin receptor $[\mathrm{s}(\mathrm{P}) \mathrm{RR}]$ protein in MCF-7 and $\mathrm{A} 549$ cells treated by carboplatin.

(a, b) Western blot analysis of MCF-7 cells (a) and A549 cells (b) treated with carboplatin (10,50 and $100 \mu \mathrm{M})$ for $72 \mathrm{~h}$. Upper panels show bands corresponding to full-length $(\mathrm{P}) \mathrm{RR}[\mathrm{fl}(\mathrm{P}) \mathrm{RR}]$ at $35 \mathrm{kDa}$ and soluble $(\mathrm{P}) \mathrm{RR}[\mathrm{s}(\mathrm{P}) \mathrm{RR}]$ at 28 $\mathrm{kDa}$. The expression of $\beta$-actin is shown as an internal control. The experiment was repeated four times and representative results are shown. The relative expression levels of fl(P)RR and s(P)RR are shown in the middle and lower panels, respectively. The bands were photographed using the ChemiDoc ${ }^{\mathrm{TM}}$ Touch Imaging System (BioRad Laboratories), and the intensity of the detected bands was quantified by Image J software. The intensity of the bands representing $\mathrm{fl}(\mathrm{P}) \mathrm{RR}$ and $\mathrm{s}(\mathrm{P}) \mathrm{RR}$ was normalized to $\beta$-actin levels, and shown as the relative protein levels to the control (the mean of control $=1$, mean \pm SEM, $n=4)$. ${ }^{*} p<0.05,{ }^{* *} p<0.01$ compared with control.

control (left column). These findings indicated that carboplatin or paclitaxel increased the (P)RR immunoreactivity in the cytoplasm, which may represent both full-length (P)RR and soluble (P)RR.

\section{Effects of anti-cancer drugs on cell proliferation and apop- tosis}

The treatment with carboplatin $(10,50$ and $100 \mu \mathrm{M})$ or paclitaxel (1, 5 and $10 \mathrm{nM})$ for 48 hours decreased the cell number of MCF7 cells (Fig. 5a) and A549 cells (Fig. 5b) dose-dependently. The treatment with $100 \mu \mathrm{M}$ carboplatin decreased the cell number to $65 \%$ of control in MCF7 cells (Fig. 5a, upper panel) and 38\% of control in A549 cells (Fig. 5b, upper panel). The treatment with $10 \mathrm{nM}$ paclitaxel decreased the cell number to $41 \%$ of control in MCF7 cells (Fig. 5a, lower panel) and $41 \%$ of control in A549 cells (Fig. 5b, lower panel).

The ratio of Bcl-2-associated $\mathrm{X}$ protein $(\mathrm{BAX}) / \mathrm{BCL} 2$ mRNA, an apoptosis marker, was studied by real-time reverse transcriptase-quantitative polymerase chain reaction 
(a) MCF-7
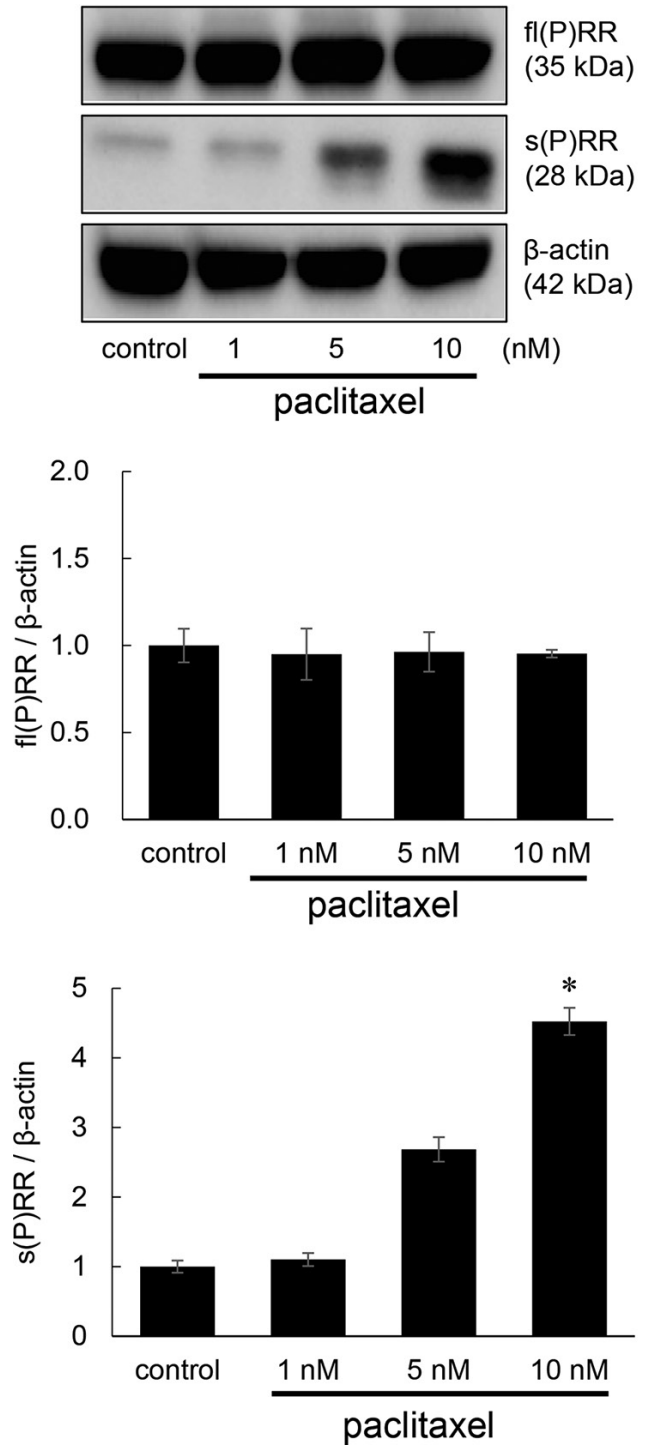

(b) A549
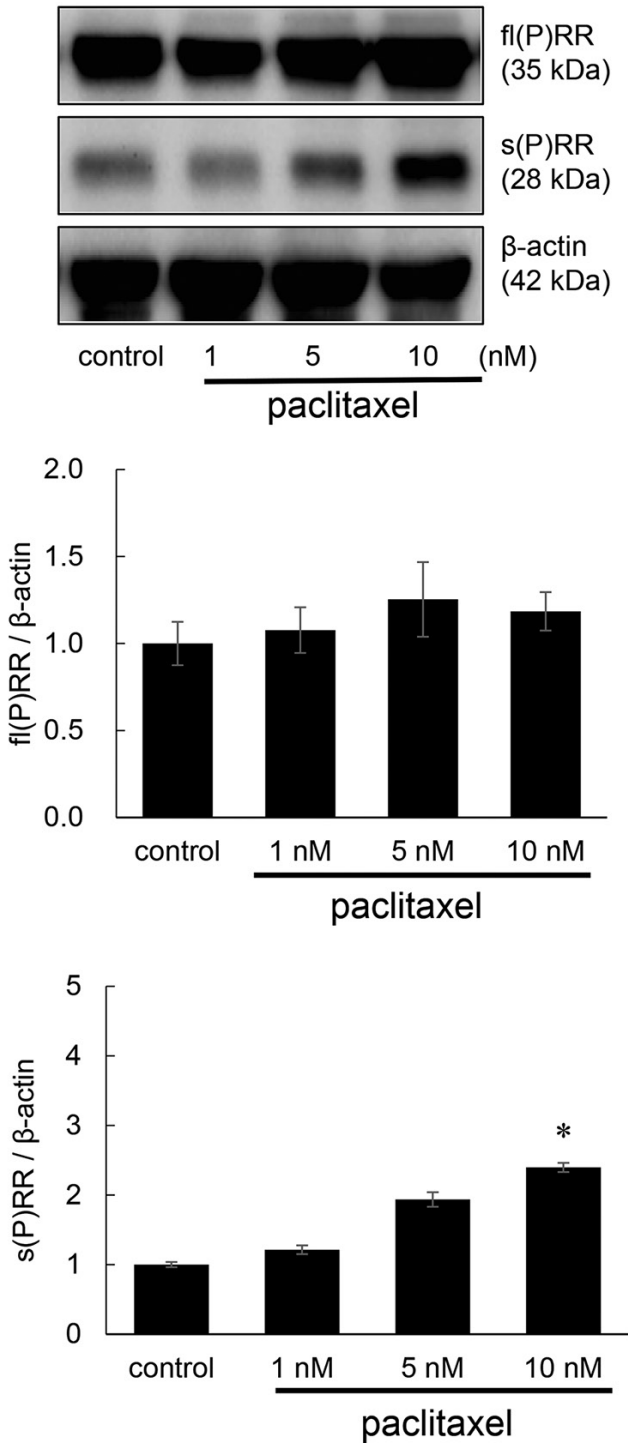

Fig. 3. Increased soluble (pro)renin receptor [s(P)RR] protein in MCF-7 and A549 cells treated by paclitaxel.

(a, b) Western blot analysis of MCF-7 cells (a) and A549 cells (b) treated with paclitaxel (1, 5 and $10 \mathrm{nM})$ for $72 \mathrm{~h}$. Upper panels show bands corresponding to full-length $(\mathrm{P}) \mathrm{RR}[\mathrm{fl}(\mathrm{P}) \mathrm{RR})]$ at $35 \mathrm{kDa}$ and soluble $(\mathrm{P}) \mathrm{RR}[\mathrm{s}(\mathrm{P}) \mathrm{RR}]$ at $28 \mathrm{kDa}$. The expression of $\beta$-actin is shown as an internal control. The experiment was repeated four times and representative results are shown. The relative expression levels of $\mathrm{fl}(\mathrm{P}) \mathrm{RR}$ and $\mathrm{s}(\mathrm{P}) \mathrm{RR}$ are shown in the middle and lower panels, respectively. The bands were photographed using the ChemiDoc ${ }^{\mathrm{TM}}$ Touch Imaging System (BioRad Laboratories), and the intensity of the detected bands was quantified by Image $J$ software. The intensity of the bands representing fl(P)RR and $\mathrm{s}(\mathrm{P}) \mathrm{RR}$ was normalized by $\beta$-actin levels, and shown as the relative protein levels to the control (the mean of control $=1$, mean \pm SEM, $n=4) .{ }^{*} p<0.05$ compared with control.

(RT-qPCR) in MCF-7 (Fig. 5c) and A549 cells (Fig. 5d) treated with $100 \mu \mathrm{M}$ carboplatin or $10 \mathrm{nM}$ paclitaxel for 48 hours. Carboplatin or paclitaxel increased the ratio of BAX/BCL2 mRNA in MCF-7 and A549 cells significantly, indicating that apoptosis occurred by carboplatin or paclitaxel (Fig. 5c, d). Immunofluorescence staining confirmed the increased number of active caspase3-positive cells in MCF7 and A549 cells treated with $100 \mu \mathrm{M}$ carboplatin (Fig. 5 e, middle column) or $10 \mathrm{nM}$ paclitaxel (right column), compared to untreated controls (left column).

\section{Activated autophagy by carboplatin or paclitaxel}

Activated status of autophagy by carboplatin or paclitaxel was confirmed in MCF-7 and A549 cells. Western blot analysis showed that carboplatin increased expression levels of LC3B-II in a concentration-dependent manner in MCF-7 (2.6-fold of control at $50 \mu \mathrm{M}$ and 2.2-fold at 100 $\mu \mathrm{M}$, both $p<0.05$ ) (Fig. 6a, lower panel) and A549 cells (1.7-fold at $100 \mu \mathrm{M}, p<0.05$ ) (Fig. 6b, lower panel), compared to control. By contrast, there was no significant increase in expression levels of LC3B-I by carboplatin in 


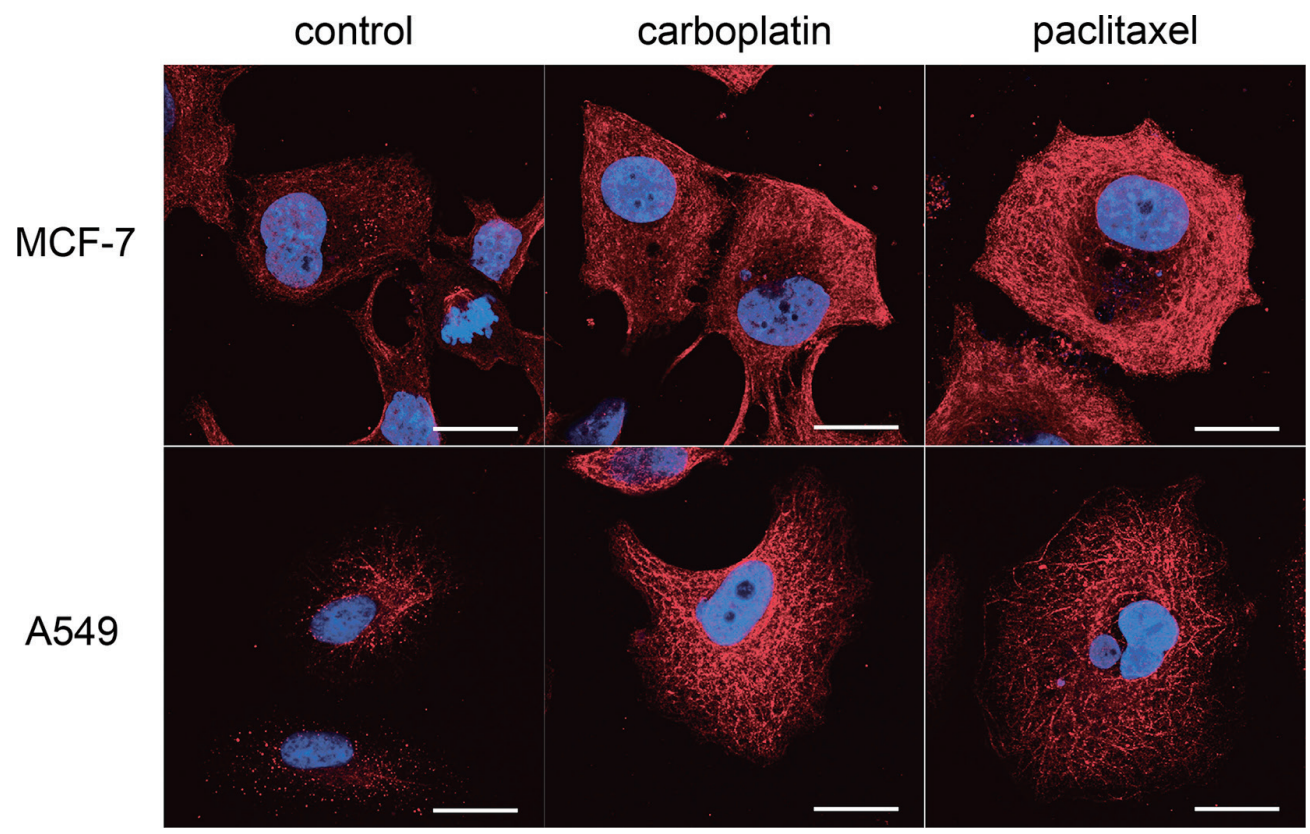

Fig. 4. Enhanced (P)RR immunoreactivity in the cytoplasm of MCF-7 (upper panel) and A549 cells (lower panel) treated with carboplatin $(100 \mu \mathrm{M})$ (middle column) or paclitaxel $(10 \mathrm{nM})$ (right column) by immunofluorescence staining. Left column shows control. Nuclei were stained with DAPI (4',6-diamidino-2-phenylindole, blue). Scale bar $=20 \mu \mathrm{m}$.

MCF-7 and A549 cells (Fig. 6a, b, middle panel).

Paclitaxel increased expression levels of LC3B-II in a concentration-dependent manner in MCF-7 (1.7-fold at 5 $\mathrm{nM}, p<0.05$ and 2.4-fold at $10 \mathrm{nM}, p<0.01$ ) (Fig. $6 \mathrm{c}$, lower panel) and A549 cells (3.5-fold at $10 \mathrm{nM}, p<0.05)$ (Fig. 6d, lower panel), compared to control. There was no significant increase in expression levels of LC3B-I by carboplatin in MCF-7 (Fig. 6c, middle panel), whereas a significant increase was noticed in A549 cells (3.3-fold at 10 $\mathrm{nM}, p<0.05)$ (Fig. 6d, middle panel).

mRNA expression levels of autophagy-related genes were studied in MCF-7 and A549 cells treated with carboplatin $(100 \mu \mathrm{M})$ or paclitaxel $(10 \mathrm{nM})$ for $48 \mathrm{~h}$. Carboplatin increased mRNA expression levels of both vesicle-associated membrane protein 8 (VAMP8) and DNA damage-regulated autophagy modulator 1 (DRAM1) in MCF-7 cells (1.2-fold of control, $p<0.05$ and 1.9-fold, $p<0.0001$, respectively) (Fig. 7a, upper panel), and in A549 cells (2.4fold, $p<0.0001$ and 2.3-fold, $p<0.0001$, respectively) (Fig. $7 \mathrm{~b}$, upper panel). Paclitaxel increased mRNA expression levels of both VAMP8 and DRAM1 in MCF-7 cells (1.4fold of control, $p<0.01$ and 1.8 -fold, $p<0.01$, respectively) (Fig. 7a, lower panel), and in A549 cells (1.5-fold, $p$ $<0.0001$ and 2.2-fold, $p<0.0001$, respectively) (Fig. 7b, lower panel).

Effects of $(P) R R$ knockdown on cell viability under the treatment of carboplatin or paclitaxel

We previously reported that small interfering RNA (siRNA)-mediated (P)RR knockdown suppressed cell viability in MCF-7 and A549 cells (Ohba et al. 2014, 2020). We wish to clarify whether or not (P)RR knockdown sup- pressed cell viability via the common pathway of carboplatin or paclitaxel. Effects of siRNA-mediated (P)RR knockdown on cell viability were therefore studied under the treatment of carboplatin $(100 \mu \mathrm{M})$ or paclitaxel $(10 \mathrm{nM})$. (P)RR knockdown by (P)RR-specific siRNA suppressed the cell viability in MCF-7 cells [ $86 \%$ of scrambled RNA (scRNA) control, $p<0.05$ ] (Fig. 8a, upper panel) and A549 cells $(71 \%$ of scRNA control, $p<0.0001)$ (Fig. 8b, upper panel) under the treatment of carboplatin. (P)RR knockdown suppressed the cell viability in MCF-7 cells ( $86 \%$ of scRNA control, $p<0.05$ ) (Fig. 8a, lower panel) and in A549 cells $(65 \%$ of scRNA control, $p<0.0001)$ (Fig. 8b, lower panel) also under the treatment of paclitaxel. RT-qPCR confirmed that (P)RR-specific siRNA suppressed the expression levels of (P)RR mRNA to about 20\%-30\% of scRNA control (Fig. 8c, d). These findings suggest that (P)RR knockdown suppressed cell viability via a different pathway of carboplatin or paclitaxel.

\section{Discussion}

The present study has shown that two different types of anti-cancer drugs, carboplatin and paclitaxel, increased the expression levels of (P)RR mRNA and soluble (P)RR protein in MCF-7 breast cancer cells and A549 lung cancer cells. In our previous study, autophagy inhibition by bafilomycin A1 or chloroquine caused the accumulation of soluble $(\mathrm{P}) \mathrm{RR}$ protein in the intracellular vesicles, presumably because of the reduced degradation of soluble (P)RR (Endo et al. 2020). In contrast to bafilomycin $A 1$ and chloroquine, both carboplatin and paclitaxel promote autophagy. In addition, apoptosis occurred in both MCF-7 and A549 cells treated by carboplatin or paclitaxel (Fig. 5). One possible 
(a) MCF-7
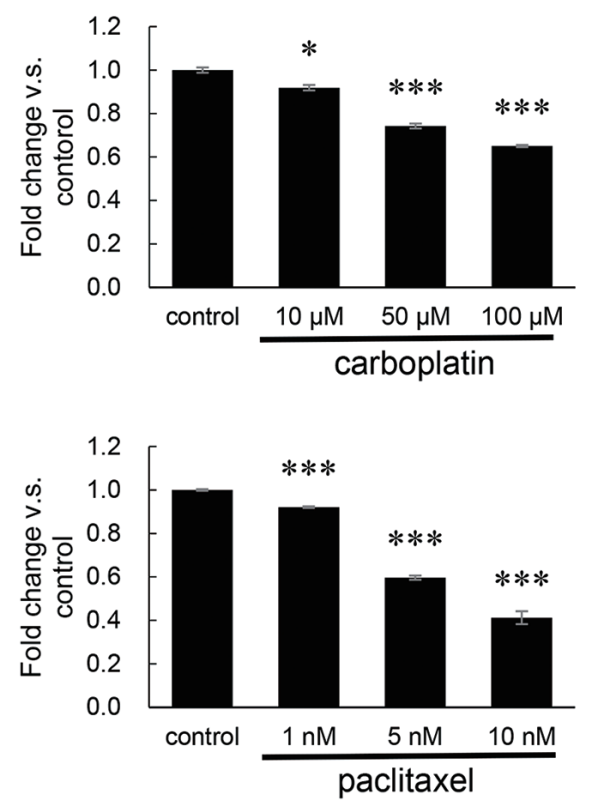

(c) MCF-7
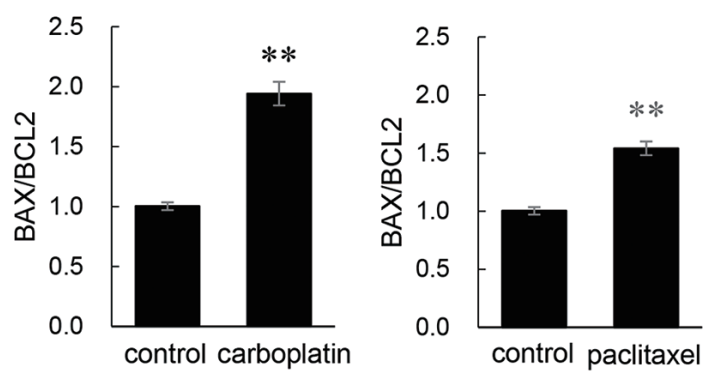

(b) A549
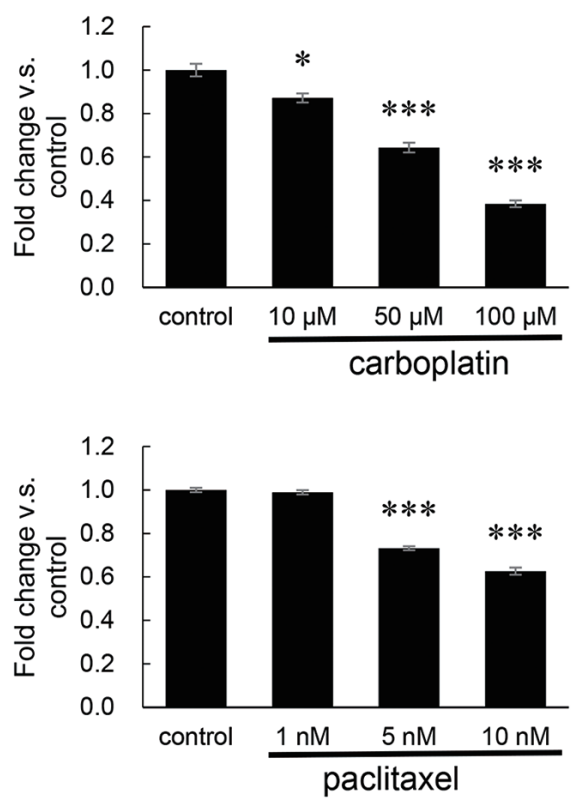

(d) A549

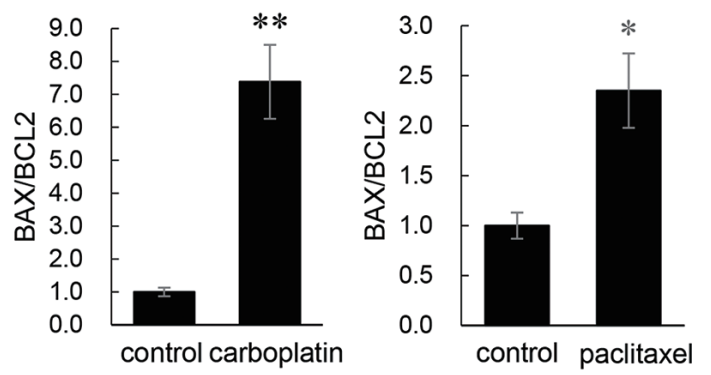

(e)

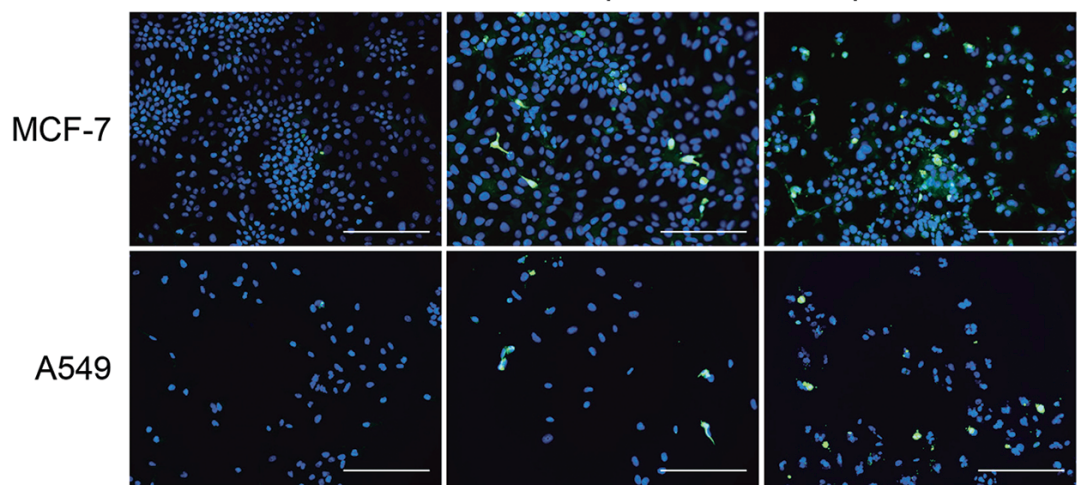

Fig. 5. Carboplatin or paclitaxel decreased the cell number of MCF-7 and A549 cells with elevated ratio of BAX/BCL2 mRNA and increased active caspase 3-positive cells.

(a, b) Cell number of MCF-7 cells (a) and A549 cells (b) treated with carboplatin (10 $\mu \mathrm{M}, 50$ and $100 \mu \mathrm{M})$ (upper panel) or paclitaxel $(1,5$ and $10 \mathrm{nM}$ ) (lower panel) for $48 \mathrm{~h}$. Relative levels to control are shown (the mean of $\operatorname{control}=1$, mean \pm SEM, $n=6) .{ }^{*} p<0.05,{ }^{* * *} p<0.0001$ compared with control. (c, d) The ratio of BAX and BCL2 mRNA levels (an apoptosis marker) in MCF-7 cells (c) and A549 cells (d) treated with carboplatin (100 $\mu$ M) or paclitaxel $(10 \mathrm{nM})$ for $48 \mathrm{~h}$. Relative levels to control are shown (the mean of control $=1$, mean \pm SEM, $n=4$ ). ${ }^{*} p<0.05,{ }^{* *} p<0.01$ compared with control. (e) Increased number of active caspase 3-positive cells in MCF7 (upper panel) and A549 cells (lower panel) treated with carboplatin $(100 \mu \mathrm{M})$ (middle column) or paclitaxel $(10 \mathrm{nM})$ (right column) for $72 \mathrm{~h}$. Left column shows control. Nuclei were stained with DAPI (4',6-diamidino-2-phenylindole, blue). Scale bar $=200 \mu \mathrm{m}$. 
(a) MCF-7
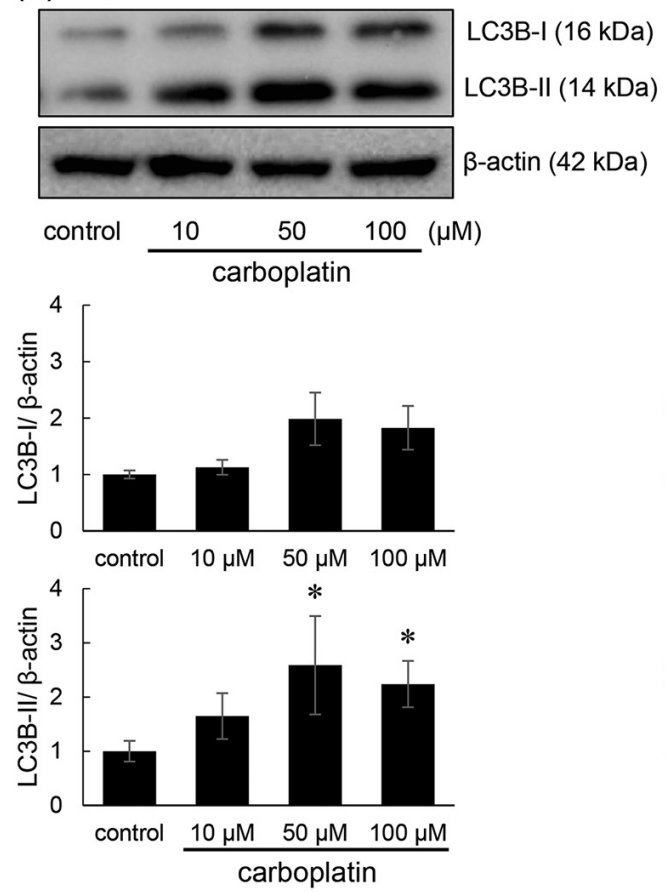

(c) MCF-7
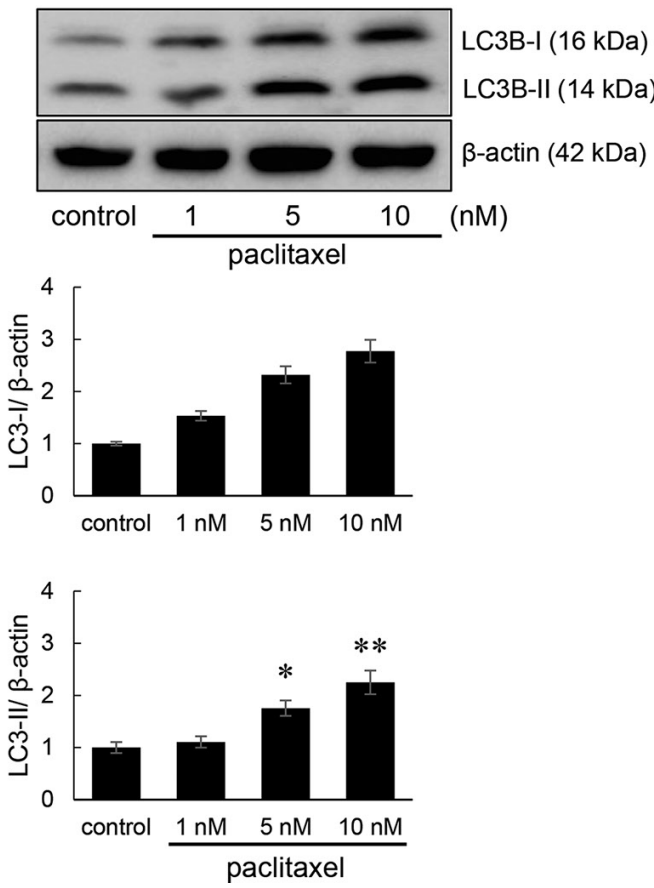

(b) A549
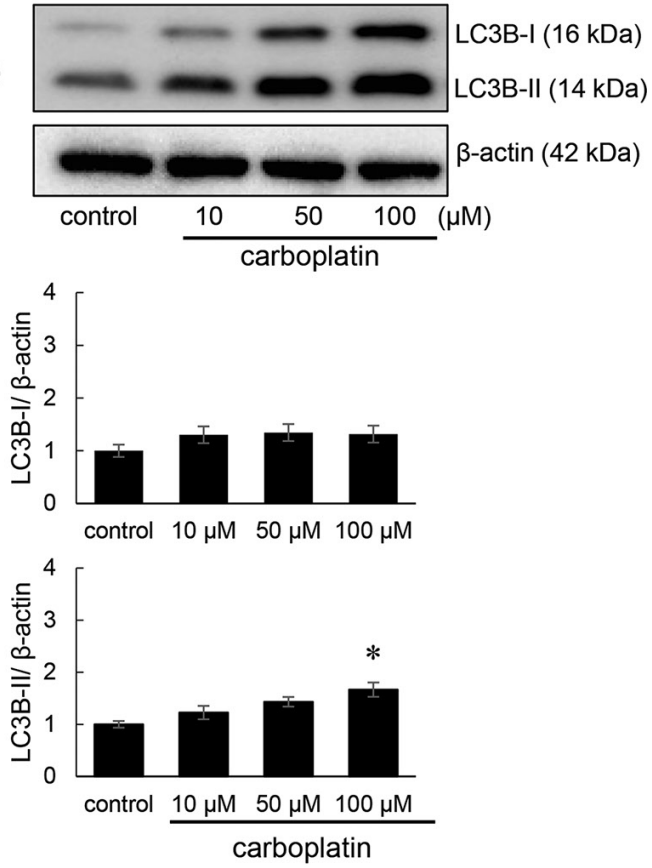

(d) A549
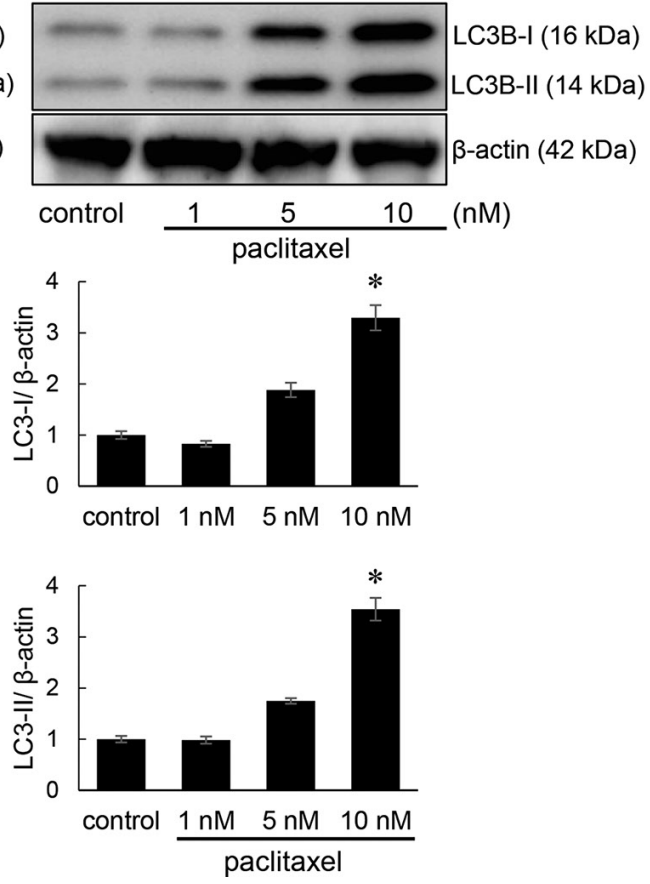

Fig. 6. Activated autophagy by carboplatin or paclitaxel in MCF-7 and A549 cells.

(a, b) Western blot analysis of LC3B-I and LC3B-II in MCF-7 cells (a) and A549 cells (b) treated with carboplatin (10, 50 and $100 \mu \mathrm{M}$ ) for $72 \mathrm{~h}$. (c, d) Western blot analysis of LC3B-I and LC3B-II in MCF-7 cells (c) and A549 cells (d) treated with paclitaxel $(1,5$ and $10 \mathrm{nM})$ for $72 \mathrm{~h}$. Upper panels show bands corresponding to LC3B-I at $16 \mathrm{kDa}$ and LC3B-II at $14 \mathrm{kDa}$. The expression of $\beta$-actin is shown as an internal control. The experiment was repeated four times and representative results are shown. The relative expression levels of LC3B-I and LC3B-II are shown in the middle and lower panels, respectively. The bands were photographed using the ChemiDoc ${ }^{\mathrm{TM}}$ Touch Imaging System (BioRad Laboratories), and the intensity of the detected bands was quantified by Image $\mathrm{J}$ software. The intensity of the bands representing LC3B-I and LC3B-II was normalized to $\beta$-actin levels, and shown as the relative protein levels to the control (the mean of control $=1$, mean \pm SEM, $n=4$ ). ${ }^{*} p<0.05, * * p<0.01$ compared with control. 
(a) MCF-7
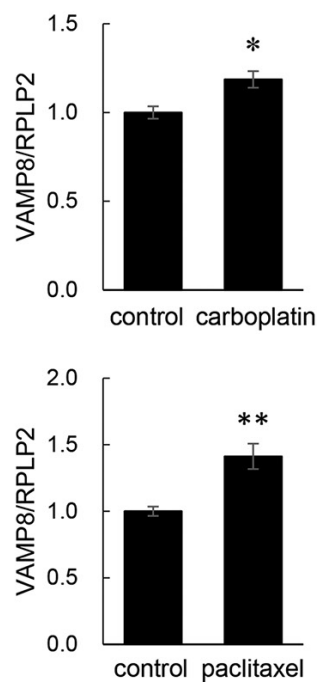
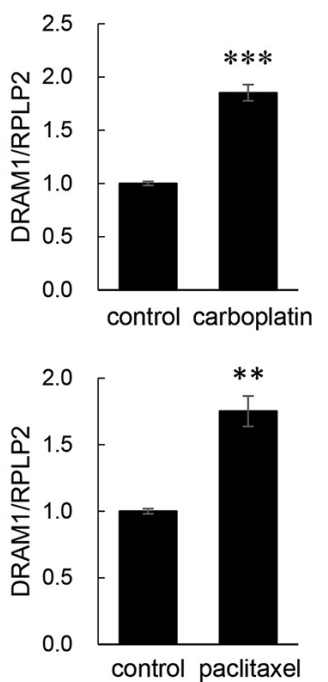

(b) A549
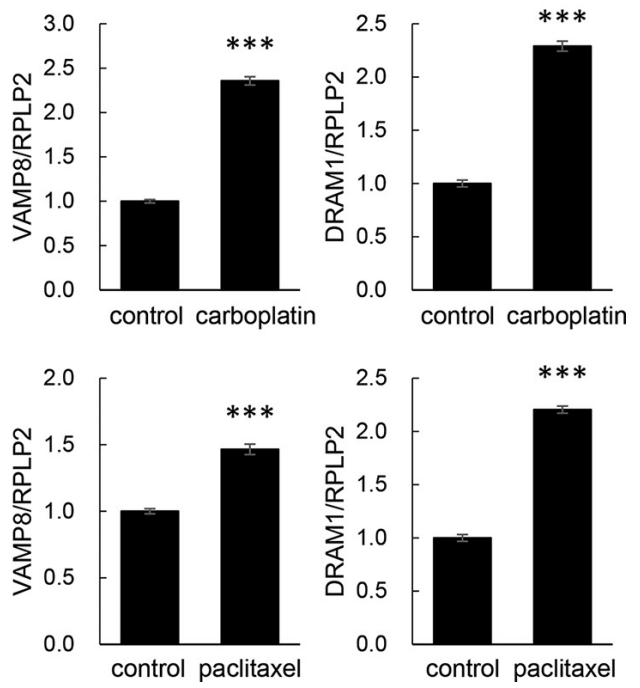

Fig. 7. Increased expression levels of autophagy-related genes, VAMP8 and DRAM1, in MCF-7 and A549 cells treated with carboplatin or paclitaxel.

VAMP8 and DRAM1 mRNA levels in MCF-7 cells (a) and A549 cells (b) treated with carboplatin (100 $\mu$ M) (upper panel) or paclitaxel $(10 \mathrm{nM})$ (lower panel) for $48 \mathrm{~h}$. The levels of VAMP8 and DRAM1 mRNA were normalized to ribosomal protein lateral stalk subunit P2 (RPLP2) mRNA and shown as the relative mRNA levels to the control (the mean of control $=1$, mean \pm SEM, $n=4) .{ }^{*} p<0.05,{ }^{*} p<0.01,{ }^{* *} p<0.0001$ compared with control.

cause for the elevated (P)RR mRNA expression by carboplatin and paclitaxel may be apoptosis caused by these anticancer drugs.

Gao et al. (2020) showed that (P)RR expression levels were upregulated by hypoxia/reperfusion together with induction of apoptosis and autophagy in H9c2 cells (Gao et al. 2020). Arundhathi et al. (2016) reported that (P)RR overexpression increased cell proliferation and suppressed apoptosis, whereas the (P)RR knockdown decreased cell proliferation and enhanced apoptosis in pancreatic cancer cells. (P)RR mRNA expression may therefore be upregulated in cultured cancer cells by apoptosis induced by anticancer drugs. In turn, upregulated (P)RR may keep cell proliferation and suppress apoptosis in cancer cells treated by anti-cancer drugs.

The crosstalk between apoptosis and autophagy is considered to play an important role in cell homeostasis (Maiuri et al. 2007; Mariño et al. 2014). Autophagy and apoptosis are induced by many stress pathways within the same cells. In certain conditions, autophagy constitutes a stress adaptation that avoids cell death and suppresses apoptosis. Anticancer drugs, carboplatin and paclitaxel, may cause stress, and elicit both apoptosis and autophagy in cancer cells. Autophagy induced by anti-cancer drugs may constitute a stress adaptation that prevents cell death in cancer cells.

It is noteworthy that the increase in soluble (P)RR is more apparent than that of full-length (P)RR in MCF-7 and A549 cells treated by carboplatin or paclitaxel. A truncated (P)RR forms a functional complex with V-ATPase, and plays a pivotal role in lysosomal acidification and autophagy (Nguyen 2011). Autophagy induced by anti-cancer drugs may require increases in the V-ATPase activity and intracellular truncated (P)RR levels. Together with truncated $(\mathrm{P}) \mathrm{RR}$, soluble $(\mathrm{P}) \mathrm{RR}$ is generated from full-length (P)RR by furin (Cousin et al. 2009), site-1 protease (Yoshikawa et al. 2011), or ADAM 19 (Nakagawa et al. 2017). Increased requirement of truncated (P)RR by autophagy may, therefore, explain elevated intracellular levels of soluble (P)RR in MCF-7 and A549 cells treated by anti-cancer drugs.

V-ATPases play an important role in the regulation of intracellular and extracellular $\mathrm{pH}$ (Fais et al. 2007). Acidic extracellular $\mathrm{pH}$ is a major feature of cancer cells, which is caused mainly by increased lactate secretion from anaerobic glycolysis (McCarty and Whitaker, 2010; Katara et al. 2016; White et al. 2017). Dysregulated $\mathrm{pH}$ affects behaviors of cancer cells, including proliferation, metastasis, and tumorigenesis. Particularly, there has been accumulating evidence that hypoxia and acidity are involved in the pathophysiology of cancer progression and in the sensitivity of cancer cells to chemotherapy. V-ATPases play an important role in the control of the tumor acidic microenvironment and has been proposed to be a target for novel strategies of cancer treatment (Fais et al. 2007).

The knockout of the (P)RR gene resulted in loss-offunction of V-ATPase, and impairs lysosomal acidification and autophagy in cardiomyocytes or renal podocytes (Kinouchi et al. 2010; Oshima et al. 2011; Riediger et al. 2011). (P)RR is abundantly expressed in the kidney, particularly the renal tubular and collecting duct cells (Hirose et al. 2010; Takahashi et al. 2010; Yamakoshi et al. 2020). Several experimental analyses reveal the importance of 
(a) MCF-7
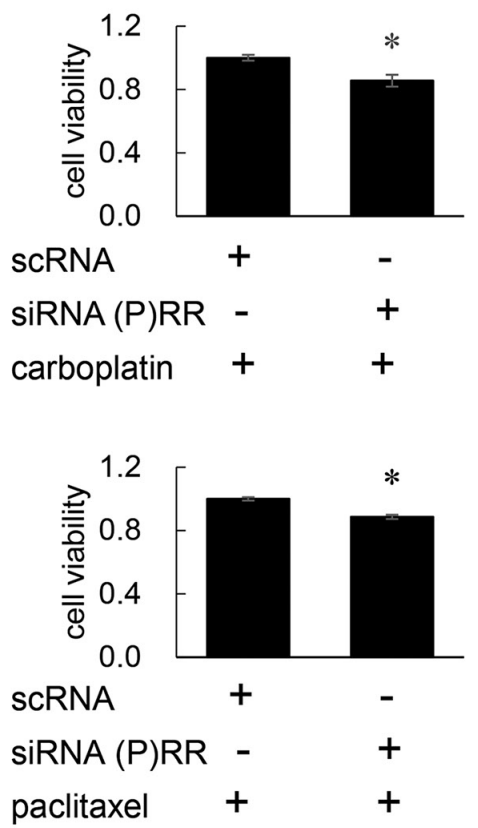

(c) MCF-7
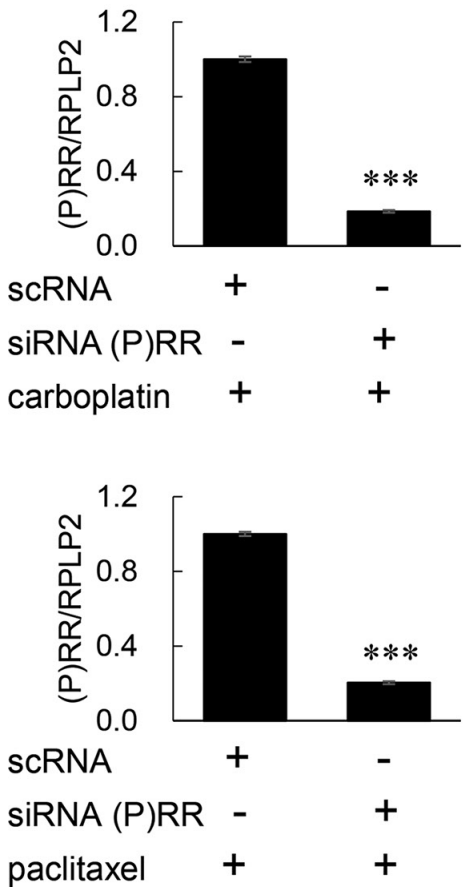

(b) A549
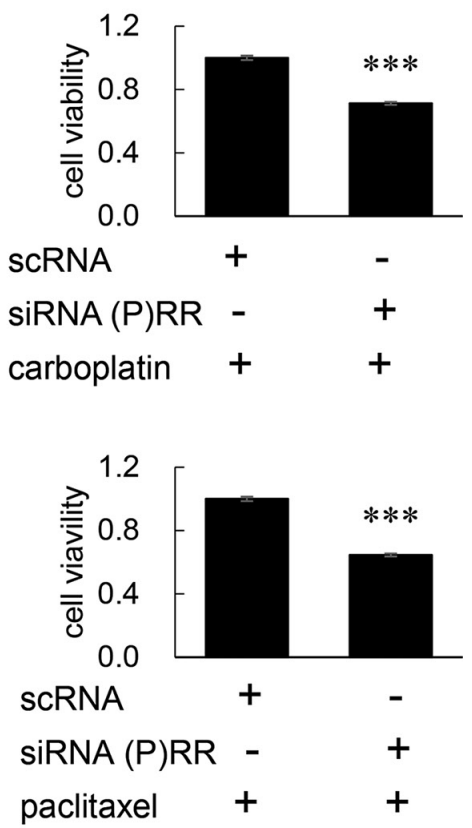

(d) A549
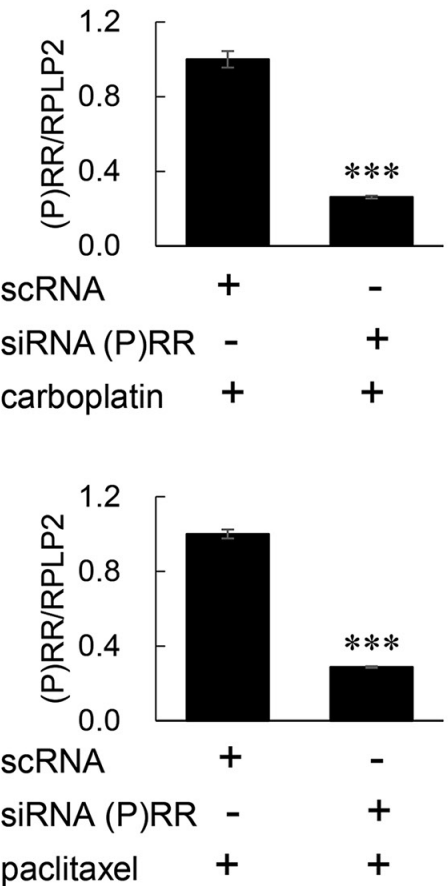

Fig. 8. Suppressed cell viability by (P)RR knockdown under the treatment of carboplatin or paclitaxel in MCF-7 and A549 cells.

(a, b) Cell viability of MCF-7 cells (a) and A549 cells (b) transfected with scrambled RNA (scRNA; control) or small interfering RNAs for (P)RR (siRNA (P)RR) under the treatment of carboplatin $(100 \mu \mathrm{M})$ (upper panel) or paclitaxel (10 $\mathrm{nM}$ ) (lower panel) for $72 \mathrm{~h}$. Cell viability was shown as the relative cell number to the control (scRNA-transfected cells) (the mean of control $=1$, mean $\pm \mathrm{SEM}, n=4)$. ${ }^{*} p<0.05,{ }^{* * *} p<0.0001$ compared with control. (c, d) Relative expression levels of (P)RR mRNA in MCF-7 cells (c) and A549 cells (d) transfected with scrambled RNA (scRNA; control) or small interfering RNAs for (P)RR (siRNA (P)RR) under the treatment of carboplatin (100 $\mu \mathrm{M})$ (upper panel) or paclitaxel $(10 \mathrm{nM})$ (lower panel) for $72 \mathrm{~h}$. The (P)RR mRNA levels are normalized to ribosomal protein lateral stalk subunit P2 (RPLP2) mRNA levels and shown as the relative mRNA levels to the control (the mean of control $=1$, mean $\pm \mathrm{SEM}, n=4) . * * * p<0.0001$ compared with control. 
(P)RR for the acid-base balance regulation in the kidney. In rat renal collecting ducts, $(\mathrm{P}) \mathrm{RR}$ localized to the apical surface of $\alpha$-type intercalated cells and colocalized with the B1/2 subunit of the V-ATPase (Advani et al. 2009). An inducible conditional deletion of (P)RR in mouse renal epithelial cells impairs acid-base regulation by suppressing V-ATPase expression and activity in the intercalated cells of the collecting duct (Trepiccione et al. 2016). Moreover, (P)RR knockdown by siRNA abolished the vasopressinstimulated V-ATPase activity in Madin-Darby canine kidney clone 11 (MDCK.C11) intercalated cells ( $\mathrm{Lu}$ et al. 2013). Thus, (P)RR plays an important role in the V-ATPase activity of the kidney and the excretion of $\mathrm{H}^{+}$ into urine. (P)RR in cancer cells may also play an important role, not only in the regulation of $\mathrm{pH}$ in intracellular compartments, but also in the secretion of $\mathrm{H}^{+}$into extracellular fluid.

Our previous studies suggested that the $(\mathrm{P}) \mathrm{RR}$ suppression decreased cell proliferation through the common pathway with bafilomycin A1, but not with chloroquine in A549 cells (Ohba et al. 2020). The present study suggested that (P)RR suppression reduced cell viability by a different pathway of carboplatin or paclitaxel (Fig. 8). This finding raises the possibility that (P)RR suppression may be a novel anti-cancer strategy which complements the action of anticancer drugs. The (P)RR suppression may result in the reduced V-ATPase activity and decrease the proliferation of cancer cells through the neutralization of extracellular $\mathrm{pH}$, and the impairment of lysosomal acidification and autophagy. In contrast, the (P)RR suppression causes other functional changes in non-neoplastic cells, such as pancreatic $\beta$ cells and adipocytes. The (P)RR gene deletion causes a dramatic accumulation of large, multigranular vacuoles in the cytoplasm, with reduced insulin content of pancreatic $\beta$ cells, but these phenotypic alterations could not be attributed to a deficiency in autophagy or acidification of lysosomes (Binger et al. 2019). Adipocyte (P)RR deficiency induces lipodystrophy and liver steatosis, and increases blood pressure and plasma soluble (P)RR concentrations (Wu et al. 2016; Gatineau et al. 2021). Therefore, further studies are required to clarify the difference in the effects of the $(\mathrm{P}) \mathrm{RR}$ suppression between cancer cells and non-neoplastic cells.

The present study has several limitations. First, the experiments were done in two cultured cell lines, but not in vivo. Further studies using experimental animals are required to clarify the effects of anti-cancer drugs on $(\mathrm{P}) \mathrm{RR}$ expression. Second, extracellular and intracellular $\mathrm{pH}$ was not measured in the cultured cells. Therefore, the effects of anti-cancer drugs and (P)RR suppression on extracellular and intracellular $\mathrm{pH}$ remain to be clarified. Third, the experiments were done in cancer cells, but not in non-neoplastic cells. The response of (P)RR expression, apoptosis and autophagy to carboplatin or paclitaxel remain to be determined in non-neoplastic cells. Finally, the increase in soluble (P)RR by carboplatin or paclitaxel was more marked than that of full-length $(\mathrm{P}) \mathrm{RR}$. Increased requirement of truncated (P)RR for autophagy may explain this increase in soluble (P)RR. However, the present study did not estimate the expression levels of truncated (P)RR.

In conclusion, the present study showed that the expression of (P)RR mRNA and soluble (P)RR was increased by anti-cancer drugs, carboplatin and paclitaxel, accompanied with increased apoptosis and autophagy. Upregulated (P)RR, together with autophagy, may constitute a stress adaptation that avoids cell death of cancer cells.

\section{Acknowledgments}

The authors are grateful to the Center of Research Instruments in the Institute of Development, Aging and Cancer (IDAC) of Tohoku University, and Center for Instrumental Analysis of Tohoku Medical and Pharmaceutical University for their technical assistance. We thank Prof. Kazuhito Totsune for providing anti-(P)RR antibody, and Ms. Chika Takahashi for assistance with qPCR analysis. This study was supported in part by Grantsin-Aid for Scientific Research (19H03677, 19K17661, 19K21596, and 20K08612) from the Ministry of Education, Culture, Sports, Science and Technology of Japan (MEXT), and in part by Takeda Science Foundation. The Division of Integrative Renal Replacement Therapy is financially supported by Chugai Pharmaceutical Co., Ltd., Terumo Corporation, and JMS Co., Ltd.

\section{Author Contributions}

Y.K.-Y. designed the research together with K.O., T.H. and K.T., and wrote the initial draft of the manuscript. Y.K.-Y., S.S., T.W., F.W. and M.E. performed cell culture experiments and western blot analysis. T.H. performed immunocytochemistry. A.E., T.H., and T.M. performed RT-qPCR analysis. All authors critically reviewed the manuscript and approved the final version of the manuscript.

\section{Conflict of Interest}

The authors declare no conflict of interest.

\section{References}

Advani, A., Kelly, D.J., Cox, A.J., White, K.E., Advani, S.L., Thai, K., Connelly, K.A., Yuen, D., Trogadis, J., Herzenberg, A.M., Kuliszewski, M.A., Leong-Poi, H. \& Gilbert, R.E. (2009) The (Pro)renin receptor: site-specific and functional linkage to the vacuolar $\mathrm{H}^{+}$-ATPase in the kidney. Hypertension, 54, 261-269.

Arundhathi, A., Chuang, W.H., Chen, J.K., Wang, S.E., Shyr, Y.M., Chen, J.Y., Liao, W.N., Chen, H.W., Teng, Y.M., Pai, C.C. \& Wang, C.H. (2016) Prorenin receptor acts as a potential molecular target for pancreatic ductal adenocarcinoma diagnosis. Oncotarget, 7, 55437-55448.

Bernhard, S.M., Seidel, K., Schmitz, J., Klare, S., Kirsch, S., Schrezenmeier, E., Zaade, D., Meyborg, H., Goldin-Lang, P., Stawowy, P., Zollmann, F.S., Unger, T. \& Funke-Kaiser, H. (2012) The (pro)renin receptor ((P)RR) can act as a repressor of Wnt signalling. Biochem. Pharmacol., 84, 1643-1650.

Binger, K.J., Neukam, M., Tattikota, S.G., Qadri, F., Puchkov, D., Willmes, D.M., Wurmsee, S., Geisberger, S., Dechend, R., 
Raile, K., Kurth, T., Nguyen, G., Poy, M.N., Solimena, M., Muller, D.N., et al. (2019) Atp6ap2 deletion causes extensive vacuolation that consumes the insulin content of pancreatic $\beta$ cells. Proc. Natl. Acad. Sci. U. S. A., 116, 19983-19988.

Chi, E.Y., Viriyapak, B., Kwack, H.S., Lee, Y.K., Kim, S.I., Lee, K.H. \& Park, T.C. (2013) Regulation of paclitaxel-induced programmed cell death by autophagic induction: a model for cervical cancer. Obstet. Gynecol. Sci., 56, 84-92.

Cousin, C., Bracquart, D., Contrepas, A., Corvol, P., Muller, L. \& Nguyen, G. (2009) Soluble form of the (pro)renin receptor generated by intracellular cleavage by furin is secreted in plasma. Hypertension, 53, 1077-1082.

Cruciat, C.M., Ohkawara, B., Acebron, S.P., Karaulanov, E., Reinhard, C., Ingelfinger, D., Boutros, M. \& Niehrs, C. (2010) Requirement of prorenin receptor and vacuolar H+-ATPasemediated acidification for Wnt signaling. Science, 327, 459-463.

Desai, S., Liu, Z., Yao, J., Patel, N., Chen, J., Wu, Y., Ahn, E.E., Fodstad, O. \& Tan, M. (2013) Heat shock factor 1 (HSF1) controls chemoresistance and autophagy through transcriptional regulation of autophagy-related protein 7 (ATG7). $J$. Biol. Chem., 288, 9165-9176.

Endo, M., Ohba, K., Sato, S., Yokota, Y. \& Takahashi, K. (2020) Increased soluble (pro)renin receptor protein by autophagy inhibition in cultured cancer cells. Genes Cells, 25, 483-497.

Fais, S., De Milito, A., You, H. \& Qin, W. (2007) Targeting vacuolar $\mathrm{H}^{+}$-ATPases as a new strategy against cancer. Cancer Res., 67, 10627-10630.

Forgac, M. (2007) Vacuolar ATPases: rotary proton pumps in physiology and pathophysiology. Nat. Rev. Mol. Cell Biol., 8, 917-929.

Gao, X., Zhang, S., Wang, D., Cheng, Y., Jiang, Y. \& Liu, Y. (2020) (Pro)renin receptor contributes to hypoxia/reoxygenationinduced apoptosis and autophagy in myocardial cells via the beta-catenin signaling pathway. Physiol. Res., 69, 427-438.

Gatineau, E., Arthur, G., Poupeau, A., Nichols, K., Spear, B.T., Shelman, N.R., Graf, G.A., Temel, R.E. \& Yiannikouris, F.B. (2021) The prorenin receptor and its soluble form contribute to lipid homeostasis. Am. J. Physiol. Endocrinol. Metab., 320, E609-E618.

Griesinger, F., Korol, E.E., Kayaniyil, S., Varol, N., Ebner, T. \& Goring, S.M. (2019) Efficacy and safety of first-line carboplatin-versus cisplatin-based chemotherapy for non-small cell lung cancer: a meta-analysis. Lung Cancer, 135, 196-204.

Hirose, T., Cabrera-Socorro, A., Chitayat, D., Lemonnier, T., Feraud, O., Cifuentes-Diaz, C., Gervasi, N., Mombereau, C., Ghosh, T., Stoica, L., Bacha, J.D.A., Yamada, H., Lauterbach, M.A., Guillon, M., Kaneko, K., et al. (2019) ATP6AP2 variant impairs CNS development and neuronal survival to cause fulminant neurodegeneration. J. Clin. Invest., 129, $2145-2162$.

Hirose, T., Mori, N., Totsune, K., Morimoto, R., Maejima, T., Kawamura, T., Metoki, H., Asayama, K., Kikuya, M., Ohkubo, T., Kohzuki, M., Takahashi, K. \& Imai, Y. (2009) Gene expression of (pro)renin receptor is upregulated in hearts and kidneys of rats with congestive heart failure. Peptides, 30, 2316-2322.

Hirose, T., Mori, N., Totsune, K., Morimoto, R., Maejima, T., Kawamura, T., Metoki, H., Asayama, K., Kikuya, M., Ohkubo, T., Kohzuki, M., Takahashi, K. \& Imai, Y. (2010) Increased expression of (pro)renin receptor in the remnant kidneys of 5/6 nephrectomized rats. Regul. Pept., 159, 93-99.

Katara, G.K., Kulshrestha, A., Jaiswal, M.K., Pamarthy, S., Gilman-Sachs, A. \& Beaman, K.D. (2016) Inhibition of vacuolar ATPase subunit in tumor cells delays tumor growth by decreasing the essential macrophage population in the tumor microenvironment. Oncogene, 35, 1058-1065.

Kinouchi, K., Ichihara, A., Sano, M., Sun-Wada, G.H., Wada, Y., Kurauchi-Mito, A., Bokuda, K., Narita, T., Oshima, Y.,
Sakoda, M., Tamai, Y., Sato, H., Fukuda, K. \& Itoh, H. (2010) The (pro)renin receptor/ATP6AP2 is essential for vacuolar $\mathrm{H}+$-ATPase assembly in murine cardiomyocytes. Circ. Res., 107, 30-34.

Kouchi, M., Shibayama, Y., Ogawa, D., Miyake, K., Nishiyama, A. \& Tamiya, T. (2017) (Pro)renin receptor is crucial for glioma development via the Wnt/beta-catenin signaling pathway. $J$. Neurosurg., 127, 819-828.

Liu, F., Liu, D., Yang, Y. \& Zhao, S. (2013) Effect of autophagy inhibition on chemotherapy-induced apoptosis in A549 lung cancer cells. Oncol. Lett., 5, 1261-1265.

Lu, X., Garrelds, I.M., Wagner, C.A., Danser, A.H. \& Meima, M.E. (2013) (Pro)renin receptor is required for prorenin-dependent and -independent regulation of vacuolar $\mathrm{H}^{+}$-ATPase activity in MDCK.C11 collecting duct cells. Am. J. Physiol. Renal. Physiol., 305, F417-425.

Maiuri, M.C., Zalckvar, E., Kimchi, A. \& Kroemer, G. (2007) Self-eating and self-killing: crosstalk between autophagy and apoptosis. Nat. Rev. Mol. Cell Biol., 8, 741-752.

Mariño, G., Niso-Santano, M., Baehrecke, E.H. \& Kroemer, G. (2014) Self-consumption: the interplay of autophagy and apoptosis. Nat. Rev. Mol. Cell Biol., 15, 81-94.

Mauvezin, C., Nagy, P., Juhász, G. \& Neufeld, T.P. (2015) Autophagosome-lysosome fusion is independent of V-ATPasemediated acidification. Nat. Commun., 6, 7007.

McCarty, M.F. \& Whitaker, J. (2010) Manipulating tumor acidification as a cancer treatment strategy. Altern. Med. Rev., 15, 264-272.

McGrogan, B.T., Gilmartin, B., Carney, D.N. \& McCann, A. (2008) Taxanes, microtubules and chemoresistant breast cancer. Biochim. Biophys. Acta, 1785, 96-132.

Murphy, W.K., Fossella, F.V., Winn, R.J., Shin, D.M., Hynes, H.E., Gross, H.M., Davilla, E., Leimert, J., Dhingra, H., Raber, M.N. \& et al. (1993) Phase II study of taxol in patients with untreated advanced non-small-cell lung cancer. J. Natl. Cancer Inst., 85, 384-388.

Nakagawa, T., Suzuki-Nakagawa, C., Watanabe, A., Asami, E., Matsumoto, M., Nakano, M., Ebihara, A., Uddin, M.N. \& Suzuki, F. (2017) Site-1 protease is required for the generation of soluble (pro)renin receptor. J. Biochem., 161, 369-379.

Nguyen, G. (2011) Renin, (pro)renin and receptor: an update. Clin. Sci. (Lond.), 120, 169-178.

Nguyen, G., Delarue, F., Burckle, C., Bouzhir, L., Giller, T. \& Sraer, J.D. (2002) Pivotal role of the renin/prorenin receptor in angiotensin II production and cellular responses to renin. $J$. Clin. Invest., 109, 1417-1427.

Nguyen, G. \& Muller, D.N. (2010) The biology of the (pro)renin receptor. J. Am. Soc. Nephrol., 21, 18-23.

Ohba, K., Endo, M., Sato, S., Kashio-Yokota, Y., Hirose, T. \& Takahashi, K. (2020) (Pro)renin receptor/ATP6AP2 is required for autophagy and regulates proliferation in lung adenocarcinoma cells. Genes Cells, 25, 782-795.

Ohba, K., Suzuki, T., Nishiyama, H., Kaneko, K., Hirose, T., Totsune, K., Sasano, H. \& Takahashi, K. (2014) Expression of (pro)renin receptor in breast cancers and its effect on cancercell proliferation. Biomed. Res., 35, 117-126.

Oshima, Y., Kinouchi, K., Ichihara, A., Sakoda, M., KurauchiMito, A., Bokuda, K., Narita, T., Kurosawa, H., Sun-Wada, G.H., Wada, Y., Yamada, T., Takemoto, M., Saleem, M.A., Quaggin, S.E. \& Itoh, H. (2011) Prorenin receptor is essential for normal podocyte structure and function. J. Am. Soc. Nephrol., 22, 2203-2212.

Riediger, F., Quack, I., Qadri, F., Hartleben, B., Park, J.K., Potthoff, S.A., Sohn, D., Sihn, G., Rousselle, A., Fokuhl, V., Maschke, U., Purfurst, B., Schneider, W., Rump, L.C., Luft, F.C., et al. (2011) Prorenin receptor is essential for podocyte autophagy and survival. J. Am. Soc. Nephrol., 22, 2193-2202.

Rossi, A., Di Maio, M., Chiodini, P., Rudd, R.M., Okamoto, H., Skarlos, D.V., Früh, M., Qian, W., Tamura, T., Samantas, E., 
Shibata, T., Perrone, F., Gallo, C., Gridelli, C., Martelli, O., et al. (2012) Carboplatin- or cisplatin-based chemotherapy in first-line treatment of small-cell lung cancer: the COCIS metaanalysis of individual patient data. J. Clin. Oncol., 30, 16921698.

Shibayama, Y., Fujimori, T., Nguyen, G., Hirose, T., Totsune, K., Ichihara, A., Kitada, K., Nakano, D., Kobori, H., Kohno, M., Masaki, T., Suzuki, Y., Yachida, S. \& Nishiyama, A. (2015) (Pro)renin receptor is crucial for Wnt/beta-catenin-dependent genesis of pancreatic ductal adenocarcinoma. Sci. Rep., 5, 8854.

Takahashi, K., Yamamoto, H., Hirose, T., Hiraishi, K., Shoji, I., Shibasaki, A., Kato, I., Kaneko, K., Sasano, H., Satoh, F. \& Totsune, K. (2010) Expression of (pro)renin receptor in human kidneys with end-stage kidney disease due to diabetic nephropathy. Peptides, 31, 1405-1408.

Trepiccione, F., Gerber, S.D., Grahammer, F., López-Cayuqueo, K.I., Baudrie, V., Păunescu, T.G., Capen, D.E., Picard, N., Alexander, R.T., Huber, T.B., Chambrey, R., Brown, D., Houillier, P., Eladari, D. \& Simons, M. (2016) Renal Atp6ap2/ (pro)renin receptor is required for normal vacuolar $\mathrm{H}+$-ATPase function but not for the renin-angiotensin system. J. Am. Soc. Nephrol., 27, 3320-3330.

Tutt, A., Tovey, H., Cheang, M.C.U., Kernaghan, S., Kilburn, L., Gazinska, P., Owen, J., Abraham, J., Barrett, S., Barrett-Lee, P., Brown, R., Chan, S., Dowsett, M., Flanagan, J.M., Fox, L., et al. (2018) Carboplatin in BRCA1/2-mutated and triplenegative breast cancer BRCAness subgroups: the TNT Trial. Nat. Med., 24, 628-637.

von Minckwitz, G., Schneeweiss, A., Loibl, S., Salat, C., Denkert, C., Rezai, M., Blohmer, J.U., Jackisch, C., Paepke, S., Gerber, B., Zahm, D.M., Kümmel, S., Eidtmann, H., Klare, P., Huober,
J., et al. (2014) Neoadjuvant carboplatin in patients with triple-negative and HER2-positive early breast cancer (GeparSixto; GBG 66): a randomised phase 2 trial. Lancet.Oncol., 15, 747-756.

Wang, J., Shibayama, Y., Zhang, A., Ohsaki, H., Asano, E., Suzuki, Y., Kushida, Y., Kobara, H., Masaki, T., Wang, Z. \& Nishiyama, A. (2019) (Pro)renin receptor promotes colorectal cancer through the $\mathrm{Wnt} /$ beta-catenin signalling pathway despite constitutive pathway component mutations. Br. $J$. Cancer, 120, 229-237.

White, K.A., Grillo-Hill, B.K. \& Barber, D.L. (2017) Cancer cell behaviors mediated by dysregulated $\mathrm{pH}$ dynamics at a glance. J. Cell Sci., 130, 663-669.

Wu, C.H., Mohammadmoradi, S., Thompson, J., Su, W., Gong, M., Nguyen, G. \& Yiannikouris, F. (2016) Adipocyte (pro)reninreceptor deficiency induces lipodystrophy, liver steatosis and increases blood pressure in male mice. Hypertension, 68, 213-219.

Yamakoshi, S., Ito, O., Rong, R., Ohsaki, Y., Nakamura, T., Hirose, T., Takahashi, K., Mori, T., Totsune, K. \& Kohzuki, M. (2020) High salt intake-increased (pro)renin receptor expression is exaggerated in the kidney of dahl salt-sensitive rats. Hypertension, 75, 1447-1454.

Yamamoto, H., Kaneko, K., Ohba, K., Morimoto, R., Hirose, T., Satoh, F., Totsune, K. \& Takahashi, K. (2013) Increased expression of (pro)renin receptor in aldosterone-producing adenomas. Peptides, 49, 68-73.

Yoshikawa, A., Aizaki, Y., Kusano, K., Kishi, F., Susumu, T., Iida, S., Ishiura, S., Nishimura, S., Shichiri, M. \& Senbonmatsu, T. (2011) The (pro)renin receptor is cleaved by ADAM19 in the Golgi leading to its secretion into extracellular space. Hypertens. Res., 34, 599-605. 